\title{
GIS and Geovisual Analysis
}

DOI:

http://dx.doi.org/10.4135/9781526421036905587

\section{Document Version}

Accepted author manuscript

Link to publication record in Manchester Research Explorer

\section{Citation for published version (APA):}

Buil-Gil, D., \& Langton, S. H. (2020). GIS and Geovisual Analysis. In P. A. Atkinson, S. Delamont, A. Cernat, R. A. Williams, \& J. W. Sakshaug (Eds.), SAGE Research Methods Foundations (SAGE Research Methods

Foundations; Vol. 1). Sage Publications Ltd. https://doi.org/10.4135/9781526421036905587

\section{Published in:}

SAGE Research Methods Foundations

\section{Citing this paper}

Please note that where the full-text provided on Manchester Research Explorer is the Author Accepted Manuscript or Proof version this may differ from the final Published version. If citing, it is advised that you check and use the publisher's definitive version.

\section{General rights}

Copyright and moral rights for the publications made accessible in the Research Explorer are retained by the authors and/or other copyright owners and it is a condition of accessing publications that users recognise and abide by the legal requirements associated with these rights.

\section{Takedown policy}

If you believe that this document breaches copyright please refer to the University of Manchester's Takedown Procedures [http://man.ac.uk/04Y6Bo] or contact uml.scholarlycommunications@manchester.ac.uk providing relevant details, so we can investigate your claim.

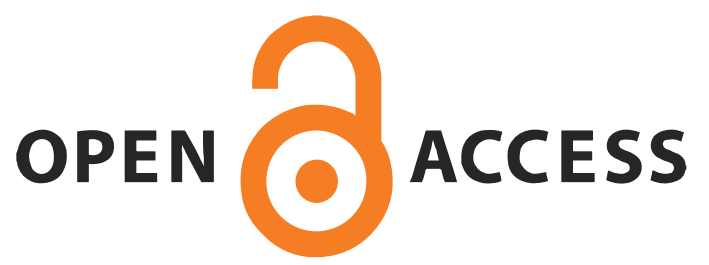




\title{
GIS and Geovisual Analysis
}

\author{
David Buil-Gil $^{1}$ and Samuel H. Langton ${ }^{2}$ \\ ${ }^{1}$ University of Manchester, UK \\ ${ }^{2}$ Manchester Metropolitan University, UK
}

Full reference: Buil-Gil, D. and Langton S. H. (2020). GIS and Geovisual Analysis. In P. A. Atkinson, S. Delamont, A. Cernat, R. A. Williams and J. W. Sakshaug (Eds.), SAGE Research Methods Foundations. SAGE.

The term 'Geographic Information Systems' (GIS) defines those computerised systems designed to gather, store, manage, visualise and analyse data with a spatial component. While GIS is generally used to refer to software applications created to manage geographic information, in truth GIS are also defined by other key components such as the spatial data being analysed, the hardware and the human component defined by users' training, experience and decisions (Ballas et al., 2018). All these are key parts of what is known as GIS, and it is why many argue that GIS should be described in terms of a conceptual and methodological framework rather than software in isolation. As such, researchers have developed an academic discipline, Geographic Information Science, aimed at examining and developing data organisation models and computational mechanisms for GIS, including geovisualisation and spatial analysis techniques (Goodchild, 2009).

The use of GIS is widespread in geography, urban planning, transport analysis, epidemiology, environmental studies and crime mapping. It is also becoming prominent in academic fields such as geodemographic classification and education planning. In practice, GIS are used to manage, visualise and analyse spatial data representing real-world features in 
order to identify spatial patterns, unveil relationships, forecast events, monitor changes and make informed decisions to set priorities and respond to incidents. For example, homicides can be represented on maps to identify rates across areas, thus assisting police forces to make operational decisions to prevent crime. The epicentres of earthquakes can be mapped to locate, characterise and predict seismic events and manage emergency measures. GIS are used to manage rare events such as wildfires, spread of diseases, storms or inundations, as well as everyday issues such as commuting routes, drug use or ethnic segregation.

GIS is an advanced research field using software which may require advanced computational skills. That said, widely used tools such as Google Maps and GPS devices have introduced many GIS functionalities to the general public. Moreover, the volume of GIS software, which vary from point-and-click interfaces to syntax-dependent tools, is larger and more diverse than ever. This chapter introduces the historical development of GIS and presents an overview of key concepts, approaches for geovisualisation and spatial analysis techniques in GIS. It summarises areas of application and available GIS software, and concludes with some final thoughts on the future of GIS.

\section{Brief history of GIS}

The earliest predecessors of GIS are ancient, hand-drawn maps. The oldest of these were depictions of the gold mines of Coptes, Egypt, during the reign of Ramses II (13th Century $\mathrm{BC}$ ), and a map of the known world in Babylonian times, which is believed to date back to the 6th Century BC. Prior to this, cave paintings and carvings representing landscapes were found in Europe. Maps became common throughout the Greek Empire, which included major 
contributions, such as that of Eratosthenes (276 BC-194 BC), the first person to calculate the Earth's circumference.

Since then, many cultures have utilised mapping techniques to shed light on spatial patterns and associations. In 1829, Balbi and Guerry visualised the geographical distribution of crimes in France, explaining the patterns observed by the unequal level of education between regions. In 1834, a French commission mapped the location of cholera deaths in Paris, which was the first geographical application of epidemiology. In 1838, the Irish Railway Commission published a series of maps representing population density by areas, geology, and the number of train passengers. Not long after, John Snow mapped occurrences of cholera in London in 1854 to determine that the source of an outbreak in Soho was a contaminated public water pump.

By the early 20th Century, the development of aerial photography and photozincography, which allowed the splitting of maps into layers, were improving the quality of maps. However, it was advances in computing which prompted the first operational GIS software. Roger Tomlinson is acknowledged as the 'father of GIS', since he coined the term itself and developed the first computerised GIS, in 1963. Tomlinson's GIS was aimed at storing and analysing spatial data about agriculture, wildlife and land use in Canada. In 1964, Howard Fisher designed SYMAP, one of the first computer GIS. By the end of the 20th Century, GIS had improved significantly. Large corporate suppliers of GIS software had emerged, geovisualisation and spatial analysis techniques became key tools across many fields, and numerous organisations integrated their use to assist operations and decision-making. Training people to use GIS has become a staple part of many educational programmes, even beyond traditional fields within geography. 


\section{Key concepts}

The diversity of topics in geographical research has motivated the collection of an enormous array of information which can be quantified, visualised and analysed using GIS. Irrespective of the source, data collected for use within GIS will inherently include some spatial component, describing the location of an entity in space, but might also incorporate attribute data, nonspatial characteristics which describe entities. There are numerous ways in which spatial data can be stored in GIS, but the most common data types are the vector and raster.

\section{Data types}

Vector data represent features in the real world through points, lines and polygons. Standing on top of a skyscraper, overlooking a city, one will observe buildings, parks, street lights and roads, each comprising discrete features of the urban landscape. Vector data is comprised of vertices, which define the geometry of these features. The simplest geometric form is a twodimensional vertex, a single $\mathrm{X}$ (longitude) and Y (latitude) coordinate describing a specific point location. When vertices are connected in order, with different start and end points, a line is formed. Lines with equal start and end points, with at least three vertices, represent polygons. In our urban landscape, points might be used to represent street lights, lines to represent roads, and polygons to represent buildings. Since these forms are representations of the real world, some decisions are down to GIS users. For instance, streets might be represented by polygons which detail the width and shape more accurately than lines. Each geometry can have associated attribute data which describe the feature, such as the height of buildings or names of streets. 
In some circumstances, vector data is unsuitable. Looking down from our skyscraper, one might also observe variation in air pollution across the city. This cannot easily or intuitively be represented using vector geometries such as lines or polygons. Air pollution might vary considerably within streets or parks, and consequently, attribute data associated with lines or polygons would mask a great deal of information. In such circumstances, raster data may be able to represent the real world more accurately than vector data. Rasters are comprised of a regular grid of cells, each of which contain associated attribute data, and can be used to represent continuous spatial information such as air pollution or remote sensing imagery of the Earth's surface. Grids are cells with the same width and height. The dimension of cells dictates the degree of precision in raster data, with larger cells potentially masking heterogeneity. Often, researchers accept some inaccuracies in their raster data to minimise the volume of data being handled. Depending on the aims of the research, some features can be represented using both raster and vector data (see Figure 1). 
Figure 1. Raster and vector data types as representations of the real world

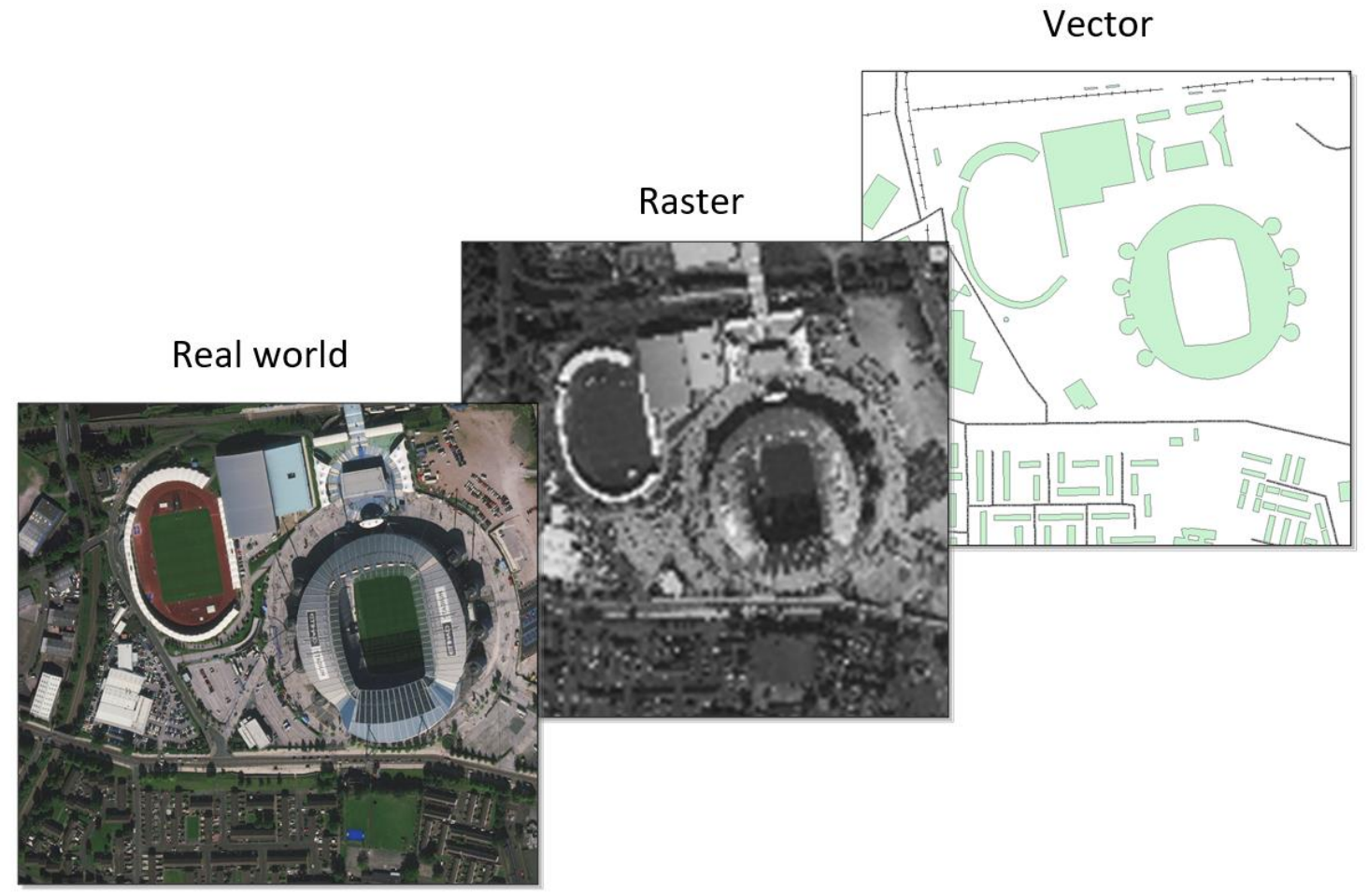

Source: authors; originally created for this entry.

\section{Projection}

A fundamental consideration when using spatial data in GIS are projections. As noted earlier, maps are representations of the real world. To represent information about the Earth, which is an oblate spheroid, using maps, which tend to be depicted on flat surfaces, a transformation is required which 'flattens' the Earth out. Doing so inevitably creates some kind of distortion. Countless different types of projections exist (see two examples in Figure 2) and are easily accessible within GIS, each of which have merits and shortcomings. The suitability of each projection is largely dependent on the data being used, such as the scale of the study area (i.e. ratio between distance on a map and such distance on the ground), and the aims of the research 
being conducted. For instance, some projections might provide accurate representations of direction but distort sizes and shapes of areas. GIS have built-in functionality to project and reproject spatial data to facilitate the visualisation of multiple data sources. In doing so, layers of vector and raster data can be built-on one another for comparison and simultaneous usage.

Figure 2. Projection examples in GIS, including the European Petroleum Survey Group (EPSG) code for each

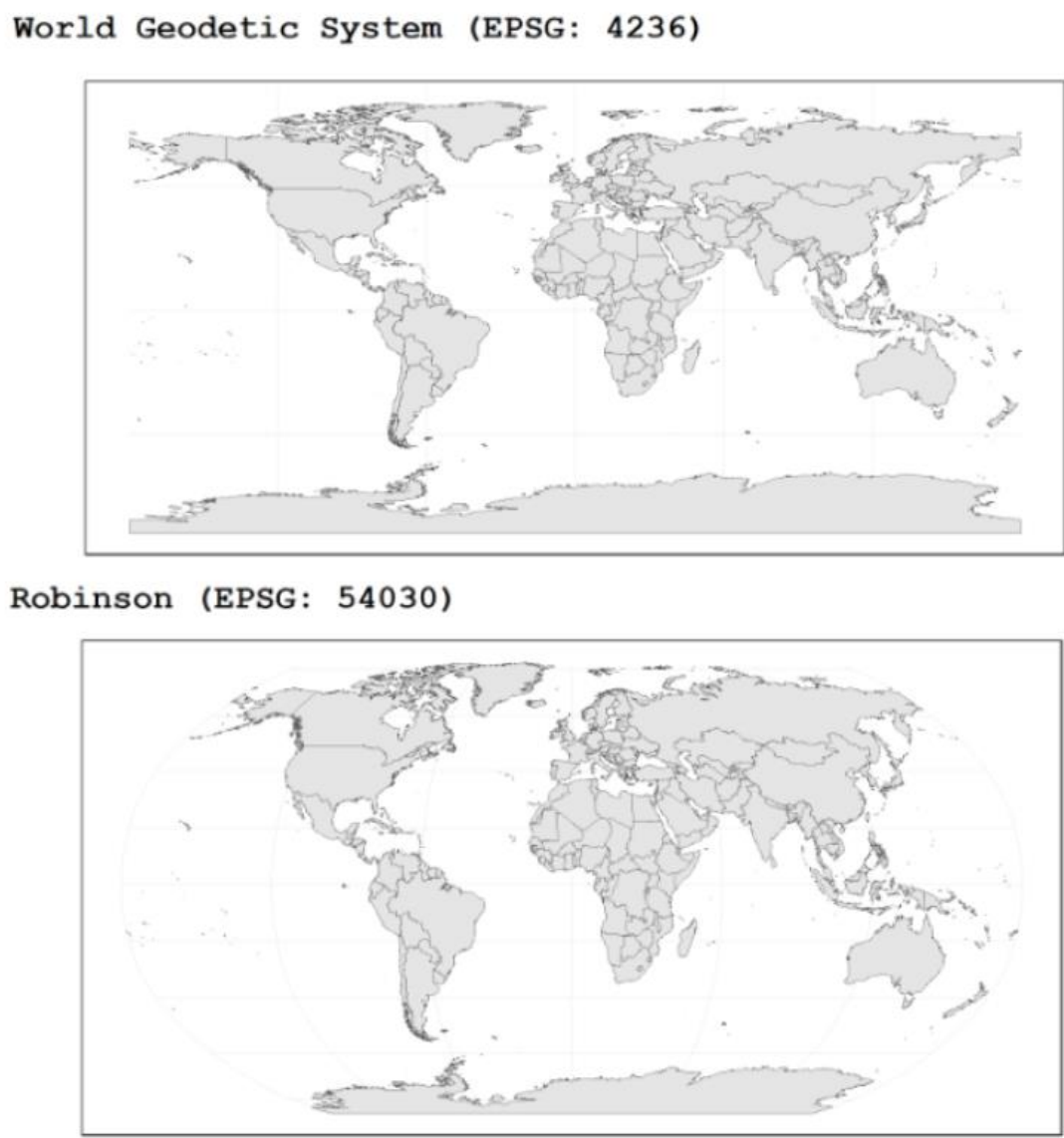

Source: authors; originally created for this entry. 


\section{Geoprocessing functions}

GIS facilitate the visualisation and analysis of geographic information through a variety of data wrangling tools. It is only through these functions that raw spatial data become meaningful, valuable and suitable for geovisualisation, analysis and dissemination. Through geocoding, geographical features such as houses or streets can be referenced and represented in GIS environments for subsequent analysis. Overlay operations are used to compare different spatial data covering the same study area simultaneously, often as a preliminary exploration. Different layers can be systematically compared and processed with joins or clips based on conditions, such as where features intersect or overlap. These functions are especially useful when collating spatial data from different sources, cleaning raw data, or aggregating information to different spatial scales. In doing so, it may also be useful to rasterise (convert from vector to raster) or polygonise (convert from raster to vector) data.

\section{Geovisualisation}

Data visualisation can broadly be defined as "the visual representation and presentation of data to facilitate understanding" (Kirk, 2019, 15). Although visualisation constitutes an accessible and aesthetically striking means for GIS researchers to convey their findings in static visual outputs such as maps and plots, the interactive exploration and analysis of geographic information also exploits the inherently visual component of geographic information. In fact, geovisualisation is mainly used to refer to the process of interactively representing spatial information while conducting explorations and analyses of geographic data (Dodge, 2014). 
GIS interfaces facilitate this interactive exploration in a manner that is unfeasible with static maps which have been printed onto paper. This interactivity opens up a diverse array of tools, amongst them, the ability to load and compare multiple datasets simultaneously, re-project and re-scale layers on the fly, convert between geometries and data types, modify colours and transparency, and automatically identify clustering of phenomena. Thus, geovisualisation is not simply a means to convey geographic information to colleagues or stakeholders, but a powerful tool with which researchers can conduct substantive research and actively engage with data. It is as much a research method for the private sphere as it is a method for conveying findings to a public audience.

Geovisualisation constitutes a fundamental knowledge-building exercise, helping derive hypotheses, identify patterns and generate avenues for future investigation. The move towards interactive, computerised visualisations, made possible through developments in GIS, represents a shift not just in the ways in which geographic information is handled and processed, but also the manner in which research is conducted. Crudely, this might be summarised as a shift away from the deductive analysis of small, bespoke datasets collected during fieldwork, to the inductive exploration of 'big data' collected remotely or through automated processes. Geovisualisation tools rise to this challenge, facilitating inquiry and unmasking unknowns rather than solely being a means to showcase findings (Slocum et al., 2009). As such, geovisualisation not only makes "a quantitative difference in the number of things a user can make visible" because it also makes "a qualitative difference in the way users think" (Maceachren \& Kraak, 1997, 335). Descriptive findings or patterns unearthed during exploratory visualisation sessions, such as observing the clustering of a phenomenon in space, might motivate the deployment of more complex spatial analyses, such as spatially-sensitive 9 
regression techniques or measures of spatial autocorrelation.

\section{Spatial data analysis}

Despite its merits, using geovisualisation as a means to explore and describe spatial data may be insufficient to explain the processes generating the data, or the underlying reasons behind the patterns observed. GIS software include tools to conduct spatial analyses aimed at giving answers to those questions that cannot be answered using geovisualisation in isolation. Inferential methods are used to shed light on unobservable spatial associations and data generation processes based on existing data and prior assumptions. For instance, we may want to know whether crime incidents cluster in certain areas of a city, and why crime is more prevalent in some areas than others. Standard significance tests rely on the assumption that observations are independent of another, which is highly problematic with spatial data. Observations tend to be affected by the values of observations at nearby locations, and phenomena often cluster near one another. The motivation for using spatial analysis is twofold: techniques adjust standard quantitative approaches to account for the attributes of spatial data, since standard techniques may violate assumptions and induce biased results; they also pursue their own objectives, such as gauging the degree of spatial clustering.

According to the typical uses of GIS, we detail below some of the main techniques for analysing spatial data. For more detailed descriptions, we refer readers to Fischer and Wang (2011) and Haining (2003).

A fundamental characteristic of geographic data is the notion of spatial autocorrelation. As the term itself implies, it measures the correlation of a variable with itself across space. A 
positive spatial autocorrelation indicates that neighbouring (or proximal) areas tend to have similar values, while a negative spatial autocorrelation indicates that these values are dissimilar, and a zero spatial autocorrelation suggests that a variable is not affected by its spatial location (see Figure 3). Most spatial analyses have their starting point in an observed positive spatial autocorrelation, which serves as a call for researchers to investigate potential spatial processes that may condition the variable of interest. Many spatial modelling approaches incorporate the spatial autocorrelation as a component of the model to investigate data generation processes, while the spatial autocorrelation may also be used on its own to examine dependencies between observations. The local Moran's I statistic is one of the main indicators of spatial autocorrelation (Anselin, 1995).

Figure 3. Spatial autocorrelation

Positive spatial autocorrelation

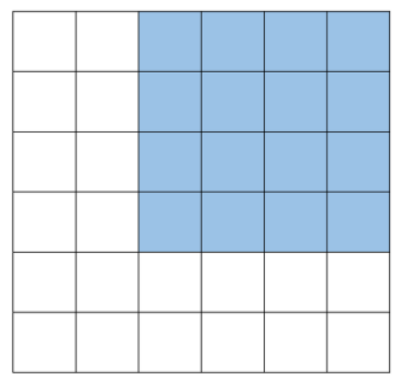

Negative spatial autocorrelation

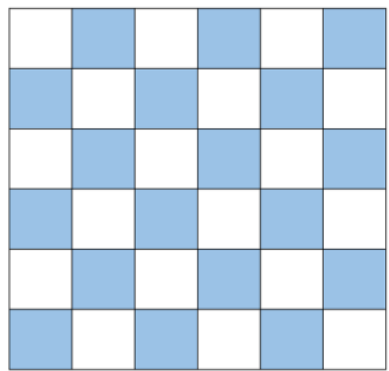

Zero spatial autocorrelation

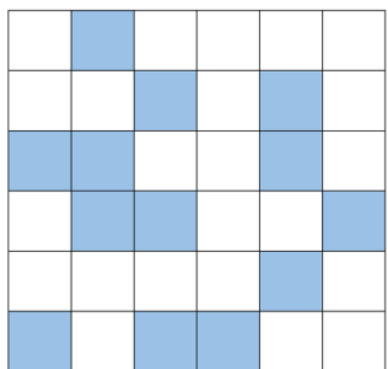

Source: authors; originally created for this entry.

Exploratory Spatial Data Analysis (ESDA) is used to identify hidden properties in data, detect patterns and formulate hypotheses. In the case of point data, these include quadrat methods and Kernel density estimation, which count the number of events per areas, defined 
typically by rectangles, and calculate the density of features in output raster cells, respectively. Nearest-neighbour methods calculate a summary statistic that tests the mean distance between nearest-neighbour points against a hypothetical condition of spatial randomness. The Kfunction takes into account distances between all events, not just nearest neighbours, to analyse spatial dependencies and estimate model parameters. Some of these can also be adopted for line geometries, while spatial autocorrelation statistics and different types of scatter plots, summary statistics and thematic maps are widely used to conduct ESDA for polygons.

Model-driven approaches are used in GIS for hypothesis testing about spatial patterns and spatial associations. As in standard inferential techniques, model diagnostics and the estimation of confidence intervals and measures of error are imperative. Spatial interpolation methods use observed points with known values to estimate values of unobserved points, thus generating a raster surface with estimates for all output grid cells. Not all spatial interpolation methods use model-based approaches. Inverse Distance Weighted (IDW) interpolation techniques weight the value of observations based on the decline of distance between known points and the unknown observations being estimated. Kriging methods are similar to IDW, though in this case a spatial autocorrelation parameter is used to determine the distance weights.

Spatial regression techniques adjust standard regression methods to consider spatial dependencies, hence providing information about spatial associations between variables. Some techniques identify the spatial dependence in the error terms, while others consider spatial fixed effects, spatially-lagged independent variables or spatially-lagged explanatory variables. Geographically weighted regressions generate parameters by observations in order to assess the coefficients' spatial heterogeneity; these detect places in which coefficients move away from their global values. Spatial Durbin models incorporate spatially-lagged independent 
variables and a spatially-lagged dependent variable. Spatio-temporal models are used to analyse data series that share spatial and temporal dependencies. Spatial dependencies can also be accounted for in other statistical techniques such as agent-based modelling, social network analysis and small area estimation.

\section{Applications and implications}

We detail four areas in which GIS are widely applied to illustrate their use across different subject domains.

\section{Environmental studies}

GIS have become a fundamental tool for helping tackle environmental challenges. These include unequal access to water resources, pollution, forest fires, oil spills, deforestation, natural disasters, endangered species and climate change. Environmental studies examine the interactions between physical, chemical and biological processes in geographical locations and their effects on the environment. GIS are used to measure, analyse and forecast bird migrations, wildlife preserves, invasive species, destruction of forests and water pollution, amongst others, thus assisting environmental management and planning aimed at maintaining natural environments. GIS allow researchers to draw spatial associations between layers of information representing physical features associated with critical environmental issues. For example, satellite data was used to identify and map forest fires in Madhya Pradesh, India, recording affected vegetation types and examining causal factors to demarcate a forest fire risk zone map (Jaiswal et al., 2002). 


\section{Epidemiology and disease mapping}

GIS are used in epidemiology to associate georeferenced social and physical phenomena to the spatial patterning of disease, health and wellbeing. For example, neighbourhood deprivation is known to be associated with mortality rates, outbreaks of yellow fever tend to occur in areas surrounding harbours, and the term 'tropical diseases' refers to diseases that occur in tropical areas. These associations were established by early epidemiologists by using hand-drawn maps. The maps of cholera cases in Paris and London in the 19th Century were early examples that illustrate the use of GIS in epidemiology. Computerised GIS are used in the surveillance and monitoring of diseases transmitted by mosquitoes and fleas, diseases caused by contaminated water, health issues associated with exposure to electromagnetic fields and nuclear facilities, contagious diseases, and pedestrian injuries and accidents. GIS are essential to design and evaluate disease management plans and, in turn, to promote public health. By way of an example, Pullan and Brooker (2012) used spatial analyses to assess the extent to which habitat characteristics determine soil-transmitted helminth infections around the world, and in doing so, identified factors associated with an increased risk of transmission.

\section{Urban planning}

Cities are complex systems composed of heterogeneous communities with evolving needs. Urban planners study the land use of urban communities and determine how to make the best possible use of available urban space. Satellite and aerial images, remote sensing and administrative datasets about resident characteristics and everyday habits are collated within GIS, visualised and analysed to gain understanding and forecast the needs of heavily populated 
areas. This might generate insights which inform decisions about where to place new residential buildings, commercial outlets, green areas and transport infrastructures. Consideration can be given to how new constructions will fit in with older structures, or how to make the best use of solar and wind energy, assessing potential environmental impacts, and taking into account the preservation of historic sites and regulatory demands. For instance, Cetin (2015) examined the distribution of green spaces in Kutahya, Turkey, to develop an integrated system of green areas that guides sustainable urban development.

\section{Environmental criminology and crime mapping}

Crime is not randomly distributed in space, and most crime incidents cluster is a small number of places. Crime rates are conditioned by demographic characteristics, as well as the urban setting and design, which can open or mitigate for criminal opportunity. For example, shopping centres generate flows of people and objects that can facilitate the converging of offenders and suitable targets. Criminologists have named those places that concentrate many people and facilitate opportunistic crimes as 'crime generators', while 'crime attractors' are areas that attract potential offenders due to known opportunities (e.g. alcohol outlets, drug trafficking areas). So-called 'crime detractors' discourage criminal activity (e.g. police stations, churches, schools). Crime analysts use GIS to overlay data about crime, social variables and locations of crime generators, attractors and detractors to study the underlying causes of deviance and design strategies to tackle problematic areas. Langton and Steenbeek (2017) used data on the physical attributes of residential homes in The Hague, Netherlands, collected using Google Street View, to examine the risk of burglary. Analysis identified the features of residential homes which increase the risk of victimisation, such as accessibility and the extent to which 
properties are under surveillance.

\section{Software}

The functionality and usability of GIS software have improved remarkably since the 1990s. Technological innovation has shaped methods to input data into GIS. In the first generation, data had to be digitalised manually, but now, information can be quantified automatically using remote sensors and aerial images. Moreover, GIS data storage capacity has increased significantly, and graphical visualisations are more powerful and diverse than they have ever been. Web-based GIS are becoming more robust and allow users to analyse spatial data from their laptops, mobile phones and tablets.

In terms of specific systems and tools, ArcGIS is the most used and arguably the most influential GIS software. It is designed and commercialised by ESRI. Generally speaking, ArcGIS is well supported and maintained. The user community is large and active online, with key materials often being publicly available to support beginners and advanced users. It remains the staple GIS software taught on Higher Education courses. Other enterprise-based GIS software are MapInfo, GlobalMapper, Manifold and Geomedia. However, the main disadvantage of commercial software is their cost. This has motivated many users to make the switch to free, open source software, which are usually supported by active and welcoming online communities. Some of the most widespread open source GIS software are QGIS, GRASS, SAGA, GeoDa and gvSIG. GeoVISTA Studio and OECD eXplorer provide specific tools for interactive geovisualisation. Moreover, spatial analytical packages to perform GIS functions are becoming widely integrated into statistical computing environments such as 
Python and R (Bivand et al., 2008). Some of the main packages for spatial analysis in R are 'sf', 'raster', 'sp', 'spatstat' and 'maptools'. Open source software tend to be at the cutting edge of the latest developments in GIS.

\section{The future of GIS}

GIS are more powerful than ever. Their usage is pervasive across many academic departments, private companies and public sector bodies. It is thus absolutely inevitable that GIS will continue to improve, both in terms of functionality and usability. Below, we provide some thoughts about potential future directions for GIS.

The availability of novel technologies for real-time data streaming creates a wide range of new opportunities for GIS. Wireless devices such as GPS and cell phones record large amounts of spatial and attribute information that may be used to better understand urban patterns. Real-time spatial data is also increasingly being recorded by the Internet of Things built into cars, public transportation and smart home devices. These technologies allow analysts to record real-time data about geographical features and structures in the field, but also facilitate the designing of tools to record information provided voluntarily by the public. Volunteered Geographic Information (VGI) proved to be an invaluable source of data for disaster response when wildfires impacted Santa Barbara, California, between 2007 and 2009. Residents used these tools to report real-time information about the location of fires and emergency shelters (Goodchild and Glennon, 2010). VGI is also used to involve the population in public processes such as decision-making for urban planning (e.g. public participation GIS). The widespread use of social media, such as Facebook and Twitter, is also an important source of real-time data 
to analyse the spatial patterning of urban perceptions, political opinions and hate speech, amongst others (Sui and Goodchild, 2011).

The incorporation of artificial intelligence, machine learning and deep learning into GIS is also creating new opportunities for automated image classification, object detection, and semantic and instance segmentation. Moreover, new technological innovations are being incorporated into GIS to produce three-dimensional and four-dimensional maps (i.e. length, width, height and time), incorporate virtual reality and augmented reality into visualisations, design web interfaces for collaborative web mapping, and visualise indoor venues and buildings.

While technological innovation provides many new opportunities to capture large amounts of spatial data, facilitating ever-more detailed and complex analyses, there is a growing risk to individual confidentiality. The issue of confidentiality in spatial data will continue to gain attention, and encourage scrutiny from the public and public representatives. The design and usage of GIS, particularly in the open source era, should be guided not just be robust research practices, but also human values, ethics and privacy.

\section{Further Readings}

Bolstad, P. (2016). GIS fundamentals: A first text on Geographic Information Systems. 5th Edition. White Bear Lake: Eider Press

Brunsdon, C., \& Comber, L. (2015). An introduction to $R$ for spatial analysis and mapping. London: SAGE.

Burrough, P. A., McDonnell, A., \& Lloyd, C. D. (2015). Principles of Geographic 18 
Information Systems. Third edition. Oxford: Oxford University Press.

Chainey, S., \& Ratcliffe, J. (2005). GIS and crime mapping. Chichester: John Wiley \& Sons.

Chang, K. (2019). Introduction to Geographic Information Systems. 9th edition. New York: McGraw Hill.

Fotheringham, A. S., Brunsdon, C., \& Charlton, M. (2000). Quantitative geography. Perspectives on spatial data analysis. London: SAGE.

Lloyd, C. D. (2010). Spatial data analysis. An introduction for GIS users. Oxford: Oxford University Press.

Longley, P. A., Goodchild, M. F., Maguire, D. J., \& Rhind, D. W. (2005). Geographic Information Systems and science. 2nd edition. Chichester: John Wiley and Sons.

Parker, R. N., \& Asencio, E. K. (2008). GIS and spatial analysis for the social sciences. Coding, mapping, and modeling. New York: Routledge.

Waller, L. A., \& Gotway, C. A. (2004). Applied spatial statistics for public health data. Hoboken: John Wiley \& Sons.

\section{References}

Anselin, L. (1995). Local indicators of spatial association-LISA. Geographical Analysis, 27(2), 93-115.

Ballas, D., Clarke, G., Franklin, R. S., \& Newing, A. (2018). GIS and the social sciences. Theory and applications. New York: Routledge.

Bivand, R. S., Pebesma, E. J., \& Gómez-Rubio, V. (2008). Applied spatial data analysis 19 
with R. New York: Springer.

Cetin, M. (2015). Using GIS analysis to assess urban green space in terms of accessibility: case study in Kutahya. International Journal of Sustainable Development \& World Ecology, 22(5), 420-424.

Dodge, M. (2014). Mapping and geovisualization. In S. C. Aitken \& G. Valentine (Eds.), Approaches to human geography. Philosophies, theories, people and practices (pp. 289-305). London: SAGE.

Fischer, M. M., \& Wang, J. (2011). Spatial data analysis. Models, methods and techniques. New York: Springer.

Goodchild, M. F. (2009). Geographic information systems and science: Today and tomorrow. Annals of GIS, 15(1), 3-9.

Goodchild, M. F., \& Glennon, J. A. (2010). Crowdsourcing geographic information for disaster response: A research frontier. International Journal of Digital Earth, 3(3), 231-241.

Haining, R. (2003). Spatial data analysis. Theory and practice. Cambridge: Cambridge University Press.

Jaiswal, R. K., Mukherjee, S., Raju, K. D., \& Saxena, R. (2002). Forest fire risk zone mapping from satellite imagery and GIS. International Journal of Applied Earth Observation and Geoinformation, 4(1), 1-10.

Kirk, A. (2019). Data visualisation. A handbook for data driven design. 2nd edition. London: SAGE.

Langton, S. H., \& Steenbeek, W. (2017). Residential burglary target selection: An analysis at the property-levelusing Google Street View. Applied Geography, 86, 292-299.

Maceachren, A. M., \& Kraak, M. J. (1997). Exploratory cartographic visualization: 20 
Advancing the agenda. Computers \& Geosciences, 23(4), 335-343.

Pullan, R. L., \& Brooker, S. J. (2012). The global limits and population at risk of soiltransmitted helminth infections in 2010. Parasites \& Vectors, 5(81).

Slocum, T. A., McMaster, R. B., Kessler, F. C., \& Howard, H. H. (2009). Thematic cartography and geovisualization. 3rd edition. Upper Saddle River: Pearson Prentice Hall.

Sui, D., \& Goodchild, M. F. (2011). The convergence of GIS and social media: challenges for GIScience. International Journal of Geographical Information Science, 25(11), $1737-1748$.

\section{All author bio(s)}

David Buil-Gil is a Research Fellow at the Department of Criminology of the University of Manchester, UK, and a member of the Cathie Marsh Institute for Social Research at this same university. He is also an associate of the Crímina Research Center for the Study and Prevention of Crime at Miguel Hernández University of Elche, Spain. His research interests cover small area estimation applications in criminology, environmental criminology, crime mapping, emotions about crime, perceptions about the police, crime reporting, new methods for data collection and open data.

Samuel H. Langton is a Research Associate for the Crime and Well-being Big Data Centre at Manchester Metropolitan University, UK. His research focuses on examining longitudinal trends in known offender residence concentrations, the estimation of non-crime police demand and spatial data visualisation. He is also interested in promoting the use of open software in social sciences. 